\title{
An Experimental Approach to the Understanding and Treatment of Hereditary Syndromes with Congenital Deafness and Hypothyroidism
}

\author{
M. S. DEOL \\ Department of Animal Genetics, University College London
}

\begin{abstract}
Summary. Hereditary syndromes with congenital deafness and hypothyroidism have been reported from many countries. The large majority of them are believed to form a single genetic entity, known as Pendred's syndrome, and inherited as a recessive trait. The anatomical basis of deafness is not known. It is generally believed that deafness and hypothyroidism are not causally related, but are independent effects of the gene. The object of this investigation was to test this view by means of induced hypothyroidism. Mice from the inbred strain C57BL/Gr were given $0.1 \%$ propylthiouracil (PTU) in drinking water, and their offspring were examined. They were found to be practically deaf, and to have serious abnormalities in the inner ear. Addition of thyroxine to the drinking water containing PTU resulted in normal hearing and a normal inner ear, showing that the abnormalities were not caused by PTU as such, but were the consequence of its inhibitory effect on thyroid function. It is, therefore, highly probable that in Pendred's syndrome and other similar conditions the loss of hearing is secondary to hypothyroidism during fetal life. Suggestions are put forward for mitigating the expressions of these syndromes by treatment with thyroxine during certain stages of development.
\end{abstract}

Hereditary deafness associated with hypothyroidism has been observed in a large number of families in many countries (full references in Fraser, 1965; McKusick, 1971). As the clinical features vary a good deal, it is not possible to say how many distinct genetic entities are involved, but the large majority of these families are similar enough to be regarded as having the same syndrome. Fraser, Morgans, and Trotter (1960) have named it Pendred's syndrome, after Vaughan Pendred who first described it in 1896. Fraser (1965) has shown that it is inherited as a recessive trait, although some minor effects of the gene may be detectable in the heterozygote. $\mathrm{He}$ gives the frequency of affected persons in the British Isles as $0.000,075$, frequency of the mutant gene causing it as 0.008 , and the mutation rate as 56 per million loci per generation. Batsakis and Nishiyama (1962) have estimated that this syndrome accounts for 1 to $10 \%$ of all hereditary deafness.

Received 29 March 1973.
The expression of Pendred's syndrome is variable. Deafness is usually quite severe. It is of the perceptive type, and is believed to be present at birth, although it may not be detected until much later. Virtually nothing is known of its anatomical basis. Hypothyroidism is not often severe, but compensatory goitre is almost invariable, so that most patients are clinically euthyroid. The best diagnostic feature is the ability of potassium perchlorate to discharge labelled iodine from the thyroid, which happens in normal persons only after administration of thiouracil (Fraser et al, 1960; Trotter, 1960). The causal relationship between deafness and hypothyroidism is not clear, and the consensus of opinion appears to be that they are independent effects of the gene (Fraser, 1965; McKusick, 1971). The object of the present investigation was to find out by means of induced hypothyroidism in mice whether deafness could be caused by hypothyroidism, and, in the event of 
affirmative results, to define the anatomical basis of resulting deafness as well as to see if it could be ameliorated by methods that might be applicable to man. Similar experiments were done by Bargman and Gardner (1967) on chick embryos, and abnormalities of the hair cells in the cochlea were found; but the value of these experiments is rather limited, because not only are the modes of gestation and the structure of the organ of hearing quite different in the chick and man, but there is no reference to hearing and the hypothyroid birds all died within 5 days of hatching. The experiments reported here are free of these drawbacks.

\section{Material and Methods}

Mice of the inbred strain C57BL/Gr were used because they were known to breed well under the desired experimental conditions (Searle, 1954). Matings were set up at the age of about 8 weeks. They were divided into four groups. In the first group they were given plain water for drinking. Their offspring, kept on plain water for their entire life, served as controls, and 20 of these animals, ranging in age from the newborn to 90 days, were examined histologically. Matings in the second group were given drinking water containing $0.1 \%$ 6-n-Propyl-2-thiouracil (PTU). Of their offspring, given the same water after weaning, 20 animals ranging from the newborn to 90 days old were examined histologically. All were born at least one month after the beginning of the treatment, often much longer. Mice in the third group were put on water containing
PTU at different stages: 10 days after the onset of pregnancy (gestation period about 21 days), 15 days after it, on the day of birth, 5 days later, 10 days later, and 14 days later. The treatment was continued with the offspring after weaning, and 30 of these animals, divided equally among the six subgroups and ranging from 14 to 120 days, were histologically examined. The fourth group were given water containing PTU to which had been added Sodium-L-Thyroxine at the rate of $90 \mu \mathrm{g} /$ $100 \mathrm{ml}$, estimated to give a daily dose of $20 \mu \mathrm{g} / 100 \mathrm{~g}$ body weight. In a few cases the amount was half of this. The treatment was begun at different stages: before the onset of pregnancy, on the day of birth, and then at intervals of 3 days up to 15 days later. It was continued with the offspring after weaning, and 37 animals, more or less equally divided among the seven subgroups and ranging from 14 to 33 days, were examined histologically.

The material was fixed in Witmaack's fluid, doubleembedded in celloidin and paraffin, sectioned at $10 \mu$, and stained with haematoxylin and orange $G$ containing a trace of erythrosin (further particulars in Deol, 1970).

A number of animals from each group and subgroup, in addition to those that were examined histologically, were subjected to hearing tests. The tests were crude, depending on the pinna response to sharp, metallic clicks, but they were regarded as quite adequate, because their results were to be used only in conjunction with histological findings.

About a dozen animals each from matings on plain water, on water containing PTU, and on water containing PTU plus thyroxine were weighed three times a week for the first 3 weeks of their life.

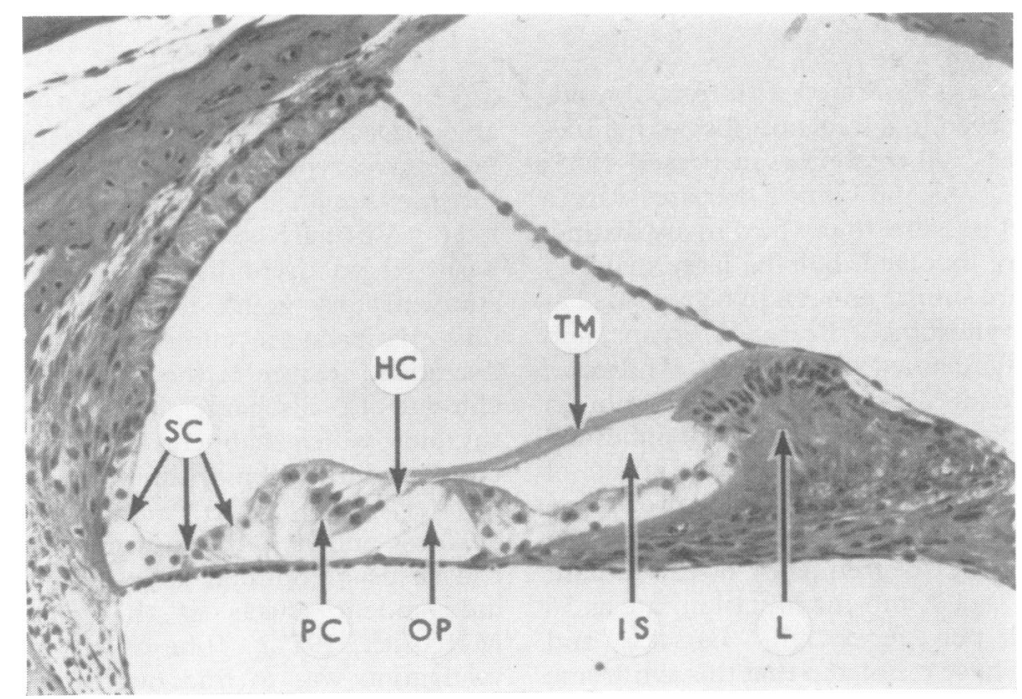

Frg. 1. Transverse section of the cochlear duct. Untreated (normal); 29 days old. HC=hair cell; IS $=$ internal spiral sulcus; L = limbus; $O P=$ outer pillar; $P C=$ phalangeal cell; $S C=$ supporting cells of various kinds; $T M=$ tectorial membrane. 


\section{Results}

The histological observations given below are confined to the cochlear duct (scala media), because clear and consistent differences were found only in this part, especially in the organ of Corti. Other structures, such as the spiral ganglion, were probably also affected, but their abnormalities were somewhat ambiguous. The developmental aspects of the organ of Corti are described in general terms, but it should be borne in mind that the basal part is always ahead of the apical part in differentiation.

No Treatment (Controls). The cochlear duct in untreated animals was normal in all respects (Fig. 1). A detailed description is unnecessary, for it closely resembles that of man, the main differences being that it makes only about $1 \frac{1}{2}$ turns around the modiolus instead of about $2 \frac{3}{4}$, and the outer hair cells in the organ of Corti form only three rows instead of the four or even five found in some regions in man.

As to its development, the gross morphogenesis was over at birth, but the fine differentiation was only in its early stages. The hair cells and phalangeal cells, although very immature, could be recognized, but the other types of supporting cells had not yet differentiated. The pillars had not yet formed properly, and there was no true internal spiral sulcus. The tectorial membrane, thick and immature, lay closely applied to the future sulcus cells. At the age of 3 days the appearance of the organ of Corti was essentially the same, except that the pillars could now be clearly identified, and the development of the tectorial membrane was a little more advanced. At 6 days the internal sulcus appeared as a narrow space under the thick tectorial membrane, and the pillars became much clearer, but in other respects the organ of Corti had not changed much since birth. During the next 3 days, however, great changes took place, so that at 9 days the organ of Corti had in many important respects assumed an adult appearance, although the outer supporting cells had not yet differentiated. The tectorial membrane had thinned markedly, and was completely free of the sulcus. During the next 3 days the tectorial membrane became still thinner, and the cells lining the sulcus matured, but in other respects there was no important change. At 15 days the tectorial membrane had thinned down to its adult form, and the differentiation of the various types of supporting cells had begun. Only minor changes took place after this. The animals began to hear at the age of 13 or 14 days.

Treatment with PTU. In the offspring of mice treated with PTU from before the onset of pregnancy the cochlear duct invariably displayed striking abnormalities of the organ of Corti, especially of the tectorial membrane (Figs. 2, 3, and 4). The membrane was always distorted, often

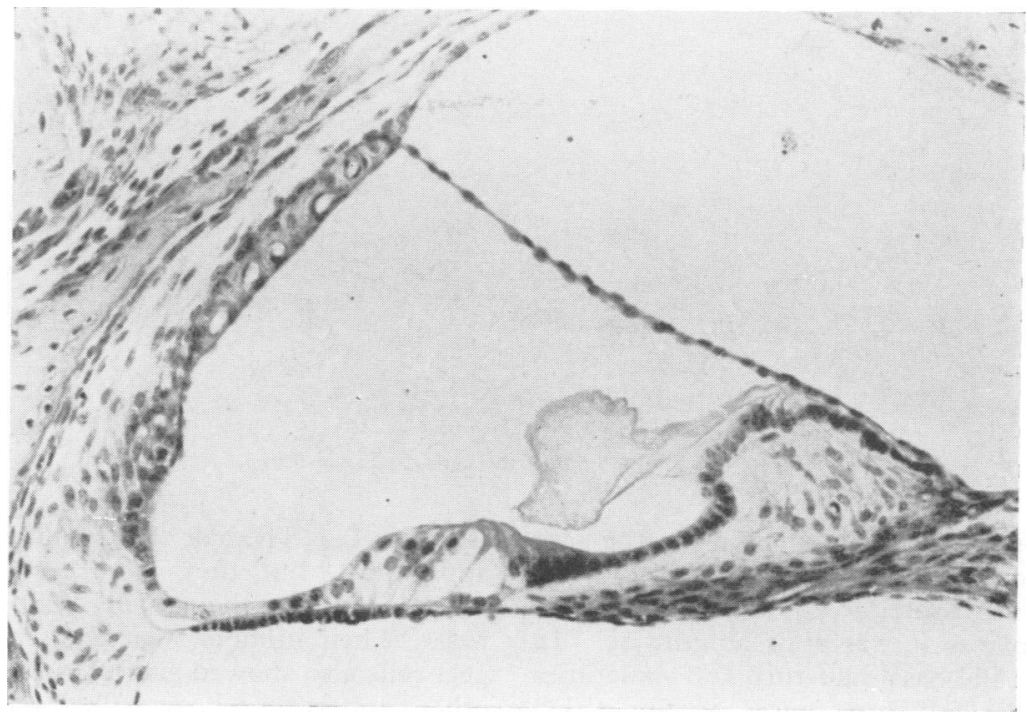

Fig. 2. Treated with PTU from before onset of pregnancy; 29 days old. 


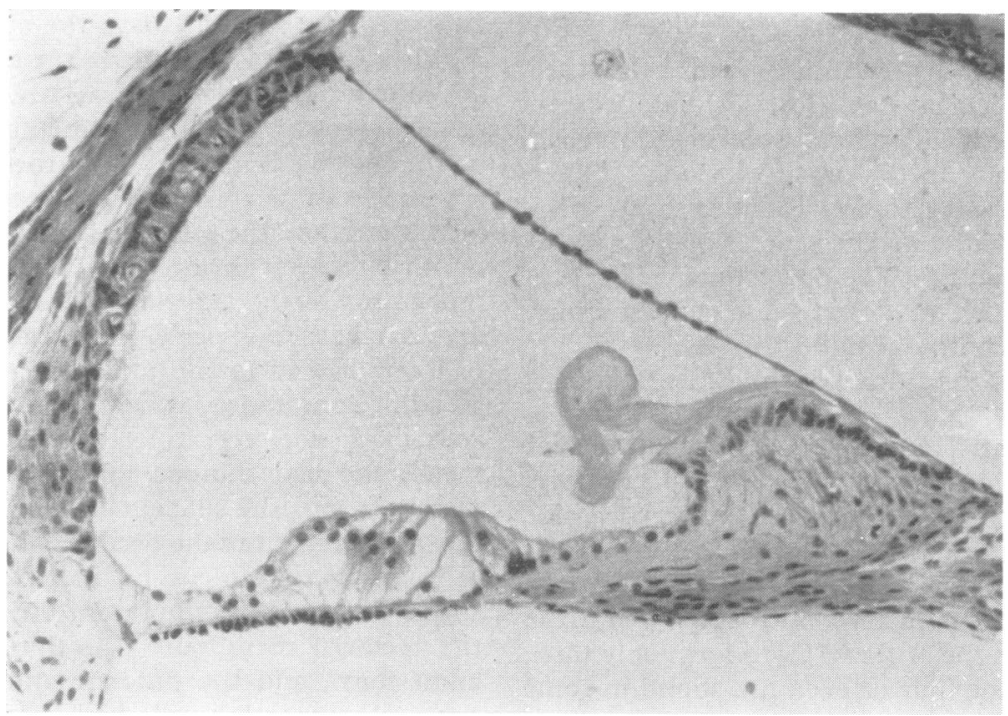

FIG. 3. Treated with PTU from before onset of pregnancy; 55 days old.

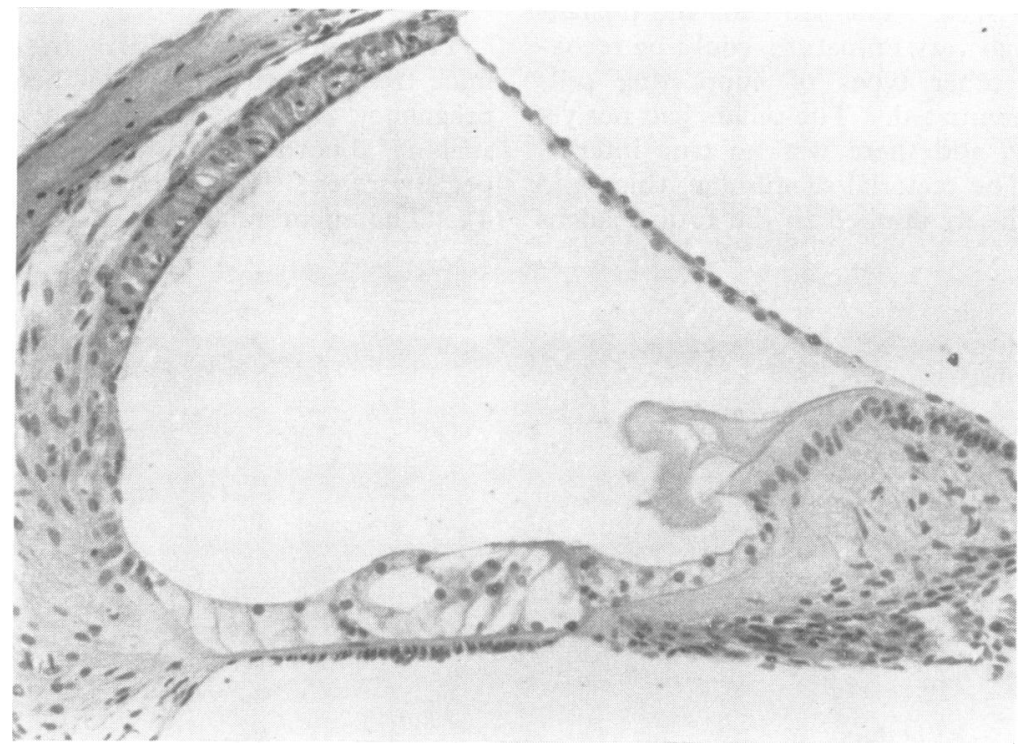

Fig. 4. Another part of the same duct as in Fig. 3.

grossly thick, and never in contact with the hair cells. The distortion was not random, but followed a pattern which was related to age and distance from the apex. In places it was split lengthwise. In older animals, in the basal half-turn and sometimes also in the middle half-turn, it was usually curled back so that its tip was in contact with the limbus (see Fig. 4). The hair cells sometimes had a normal appearance, but they were usually smaller and irregular in size, their nuclei failing to form a neat row. Their number was often reduced. Phalangeal cells also showed similar irregularities, and the other supporting cells were less well differentiated.

In the development of the cochlear duct there 
was no significant difference from the normal up to the age of 6 days. But whereas in normal mice the differentiation of the organ of Corti took great strides in the next 3 days, in PTU-treated mice little happened except for some distortion of the tectorial membrane in the basal part of the cochlear duct. The distortion had spread to the middle part by 12 days, but the membrane was still closely adhering to the internal spiral sulcus, which had not yet matured. At 15 days the distortion was visible throughout the duct, and the membrane was sometimes split lengthwise, its distal end withdrawn from the hair cells and resting on the sulcus lining. Other parts of the organ of Corti had made a little progress, the tunnel having appeared in the basal part, and phalangeal cells having lengthened somewhat. As a result of this slow pace of differentiation the general appearance of the organ at 29 days (see Fig. 2) was not quite comparable to that in normal mice at 9 days. The tectorial membrane had meanwhile grown still more abnormal, its distal end now either floating free or resting on the sulcus lining or curled back to touch the limbus. In older mice the organ of Corti assumed a little more mature form in general. Hearing was non-existent or very poor, never appearing before the age of 4 weeks.

The appearance of the cochlear duct was not any different when the treatment was begun 10 days after the onset of pregnancy, and only minor differences were observed when it was begun 15 days after it.
The same applies to hearing. However, striking improvement occurred if it was delayed until the day of birth. Hearing then was quite good, and the differentiation of the cochlear duct, although slowed down, was much closer to normal. The irregularities of the tectorial membrane were less marked and it was in contact with the hair cells to a large extent. When the treatment was begun 5 or 10 days after birth the organ of Corti as well as hearing were more or less normal, although a little slower to develop. Treatment beginning at 14 days had no apparent effects.

Treatment with PTU plus Thyroxine. When thyroxine was added to the drinking water containing PTU before the onset of pregnancy, the organ of Corti and hearing were normal, and developed at a normal rate (Fig. 5). The same happened when thyroxine was added on the day of birth, but when it was added 3, 6 , or 9 days after birth, minor abnormalities were observed in the tectorial membrane (Fig. 6). These, however, did not affect its relationship with the hair cells or affect hearing markedly. Addition of thyroxine at 12 days failed to bring about any striking improvement in the organ of Corti or hearing. The tectorial membrane remained thick and out of contact with the hair cells, although the differentiation of the hair cells and supporting cells was clearly better. At 15 days its effects were even slighter, if any.

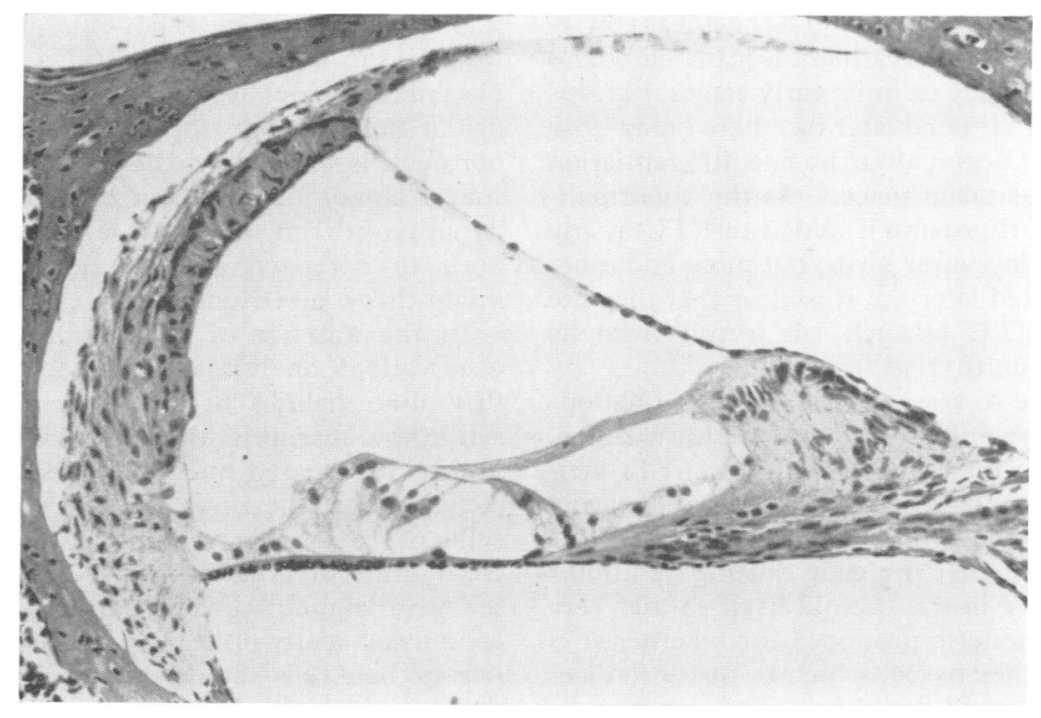

FIG. 5. Treated with PTU plus thyroxine from before onset of pregnancy; 30 days old. 


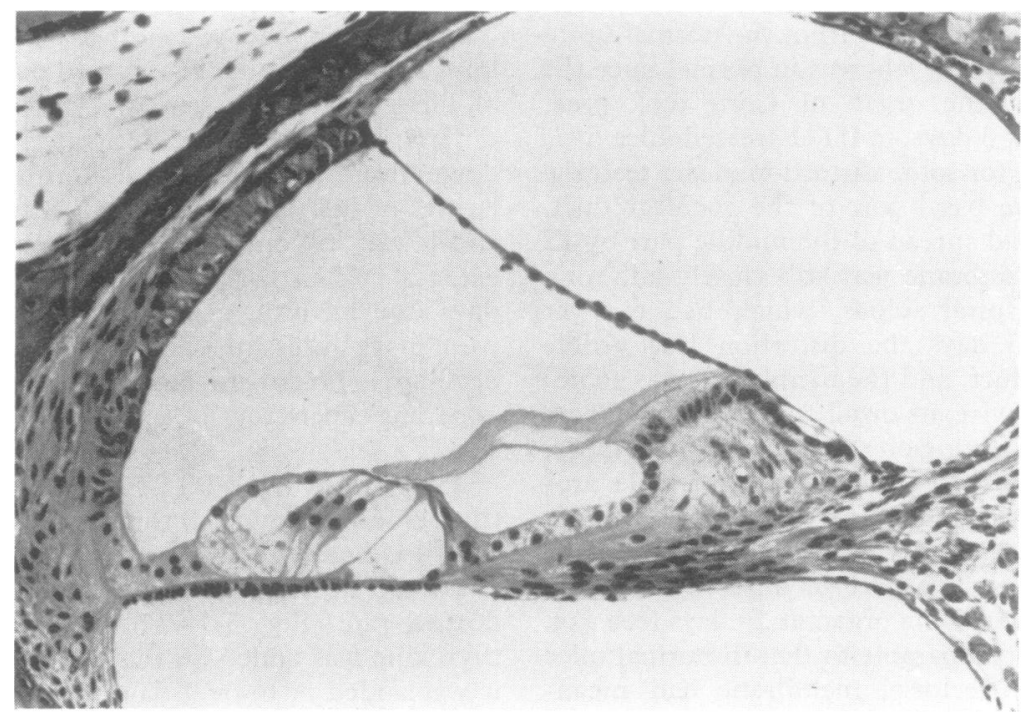

The results of these experiments may be summarized as follows. Administration of PTU to female mice leads to abnormalities of the cochlea and impaired hearing in their offspring. The loss of nearing can be fully accounted for by the cochlear abnormalities, for contact of the tectorial membrane with the hair cells is essential for normal hearing, but it remains possible that other parts of the auditory pathways are also affected. The cochlear abnormalities are severe if the treatment is initiated before the onset of pregnancy or in its early stages, but less and less so if it is initiated later on, there being little or no effect if it is begun after the fine differentiation of the cochlea has taken place. As the abnormalities are absent if thyroxine is added to PTU at any time up to a few days after birth, but more and more severe if it is added later on, it is clear that they are not caused by PTU as such, but result from its inhibitory effect on thyroid function.

It is reasonable to assume that a similar relationship between thyroid function and cochlear differentiation exists in man, and that in Pendred's syndrome and other similar conditions the loss of hearing is secondary to congenital hypothyroidism. The question arises whether the gene causing Pendred's syndrome is active in the thyroid itself so that very little or no hormone is produced, or whether it is active in some other tissue, which in turn produces an inhibitor of thyroid function. This can best be answered by testing the serum of clinically hypo- thyroid persons with this syndrome for the presence of such an inhibitor. There seems to be only one report of such a test (Fraser, 1965). The results were negative, but it is not clear whether the subject was euthyroid or hypothyroid. Howevers if the thyroid itself is the site of gene activity, then the gene probably leads to the absence of some enzyme, presumably a peroxidase, that incorporates the inorganic iodide into the thyroxine molecule, as suggested by Trotter (1960). In either case, it would seem necessary to postulate that in man the placenta does not let the hormone through in sufficient amounts, or the fetal requirement of the hormone is too high to be met from the maternal source alone, for the heterozygous mothers are not hypothyroid. A comparison of affected persons born to heterozygous and homozygous mothers might throw more light on this point.

In the absence of any satisfactory histological observations on human material, we may assume that abnormalities of the inner ear in Pendred's syndrome resemble those in PTU-treated mice. Both PTU-treated mice and affected persons have some residual hearing, and there are enough hair cells of reasonably normal appearance in PTUtreated mice to account for it. Although contact of the tectorial membrane with the hair cells is essential for normal acuity of hearing, there is no reason why normal hair cells should not give some response in the absence of this contact, especially if the sound is loud. It may be significant that when thyroxine 
was added 12 days after birth the tectorial membrane remained out of contact with the hair cells, but a greater number of hair cells had a normal appearance, and the hearing was noticeably improved. The range of residual hearing in affected persons is much greater than in PTU-treated mice, but this is undoubtedly related to the greater genetic variation in man.

The cochlear abnormalities described here are peculiar to PTU-treatment. They have not been observed before in any mutant (Deol, 1968), nor do they in any way resemble the pathological changes that appear in this strain in old age (Kocher, 1960). It is possible that general retardation consequent on hypothyroidism plays some part in their origin, but it is certainly not the main cause, for the addition of thyroxine led to a normal development of the cochlea without restoring normal growth (Fig. 7). Thyroxine, therefore, has a specific effect on the differentiation of the cochlear duct, especially on the hair cells and the tectorial membrane. Furthermore, the membrane seems to lose its capacity to respond to the hormone earlier than the hair cells. This may account for the fact that even when affected persons are euthyroid, their hearing is impaired: an improvement in thyroid function with age would not have any effect on the tectorial membrane, which would remain abnormal.

It might be possible to mitigate the expression of Pendred's syndrome by treatment with thyroxine during the critical stage of cochlear development. At first sight it appears that the critical stage in the mouse occurs at the age of 6 to 9 days, but scrutiny shows that it may last much longer. For instance,

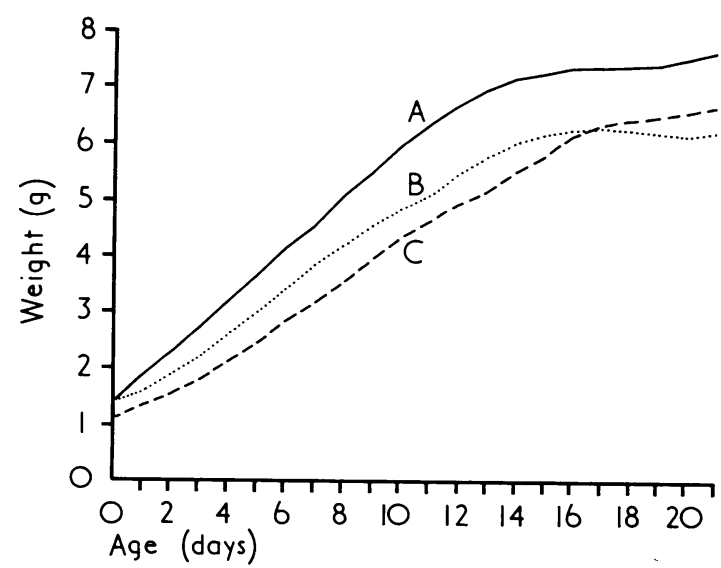

FIg. 7. Effects of PTU and PTU plus thyroxine treatments on growth. $\mathrm{A}=$ untreated (12 animals); $\mathrm{B}=$ treated with PTU (13 animals); $\mathrm{C}=$ treated with PTU plus thyroxine (13 animals). the abnormalities are strikingly milder if PTU treatment is begun at birth than if it is begun earlier. Also, there is great improvement if thyroxine is added 9 days after birth. So for the purposes of treatment we may take the critical period in the mouse to last from a little before birth to the age of about 10 days. In man, the maturation of the cochlear duct is a very slow process which begins at the base and gradually progresses towards the apex, and the comparable period probably lasts from the fourth to the seventh month of pregnancy (Streeter, 1918; Bast and Anson, 1949; Patten, 1968; Hamilton and Mossman, 1972), although there appears to be considerable variation in this respect. As the placenta does not seem to allow the hormone to pass through, thyroxine would have to be administered direct to the fetus during this period, although the placental barrier might not be so effective if triiodothyroxine is used instead. It is possible that if the hormone is injected into the amniotic cavity it might be absorbed by the fetus. In any event, in all suspected cases the infant should be treated with thyroxine during the first few weeks of life, for owing to the retardation of cochlear differentiation caused by hypothyroidism the critical period may well extend into early infancy. Where very strong grounds exist for suspecting that the fetus is affected, it may be advisable to induce birth before term so that the treatment could begin when the chances of success are greater.

Dr W. R. Trotter's generous and frequent advice is acknowledged with gratitude. Thanks are due to $\mathrm{Mr}$ D. J. Patterson and Miss Gillian Skinner for technical assistance.

\section{REFERENCES}

Bargman, G. J. and Gardner, L. I. (1967). Otic lesions and congenital hypothyroidism in the developing chick. Fournal of Clinical Investigation, 46, 1828-1839.

Bast, T. H. and Anson, B. J. (1949). The Temporal Bone and the Ear. Charles C. Thomas, Springfield.

Batsakis, J. G. and Nishiyama, R. H. (1962). Deafness with sporadic goiter (Pendred's syndrome). Archives of Otolaryngology, 76, 401-406.

Deol, M. S. (1968). Inherited diseases of the inner ear in man in the light of studies on the mouse. Fournal of Medical Genetics, 5, 137158.

Deol, M. S. (1970). The relationship between abnormalities of pigmentation and of the inner ear. Proceedings of the Royal Society, Series B, Biological Sciences, 175, 201-217.

Fraser, G. R. (1965). Association of congenital deafness with goitre (Pendred's syndrome). Annals of Human Genetics, 28, 201-249.

Fraser, G. R., Morgans, M. E., and Trotter, W. R. (1960). The syndrome of sporadic goitre and congenital deafness. Ouarterly Fournal of Medicine, 29, 279-295.

Hamilton, W. J. and Mossman, H. W. (1972). Human Embryology, 4th edtion. W. Heffer and Sons, Cambridge.

Kocher, W. (1960). Untersuchungen zur Genetik und Pathologie der Entwicklung spät einsetzender hereditärer Taubheit bei der Maus (Mus musculus). Archiv für Ohren-Nasen-und Kehlkopf- 
heilkunde vereinigt mit Zeitschrift für Hals-Nasen-und-Ohren Heilkunde. 177, 108-145.

McKusick, V. A. (1971). Mendelian Inheritance in Man, 3rd edition. The Johns Hopkins Press, Baltimore.

Patten, B. M. (1968). Human Embryology, 3rd edition. McGrawHill, New York.

Pendred, V. (1896). Deaf-mutism and goitre. Lancet, 9, 532.

Searle, A. G. (1954). Genetical studies on the skeleton of the mouse. XI. The influence of diet on variation within pure lines. Fournal of Genetics, 52, 413-424.

Streeter, G. L. (1918). The histogenesis and growth of the otic capsule and its contained periotic tissue spaces in the human embryo. Contributions to Embryology, 7, 5-54. Carnegie Institute, Washington.

Trotter, W. R. (1960). The association of deafness with thyroid dysfunction. British Medical Bulletin, 16, 92-98. 